\title{
Identification of Crizotinib Major Degradation Products Obtained Under Stress Conditions by RP-UHPLC-HRMS
}

\author{
(1) Kristina Tolić, ${ }^{1}$ Mislav Runje, ${ }^{2}$ () Tatjana Gazivoda Kraljević, ${ }^{1}$ (1) Dragana Mutavdžić Pavlović1,*
}

\author{
1 University of Zagreb, Faculty of Chemical Engeneering and Technology, Marulićev trg 19, 10000 Zagreb, Croatia \\ 2 Pliva Croatia TAPI R\&D, Prilaz baruna Filipovića 25, 10000 Zagreb, Croatia \\ * Corresponding author's e-mail address: dmutavdz@fkit.hr \\ RECEIVED: March 25, 2021 * REVISED: June 12, 2021 * ACCEPTED: June 19, 2021
}

\begin{abstract}
The pharmaceutical industry routinely performs stability testing on new compounds before they are marketed to ensure their efficacy, quality, and safety. The focus of this study was to apply forced degradation as one of the stability testing methods to investigate the stability of crizotinib, an anticancer drug, and to gain insight into the degradation pathway and degradation products formed. The forced degradation study for crizotinib was performed under acidic and alkaline hydrolysis, oxidation, photolysis and thermal conditions. Drug degradation was observed under oxidative conditions. The structures of the three major degradation products formed by oxidative degradation were identified and characterized by UHPLC/QTOF/MS/MS studies and their possible fragmentation pathways were suggested. The toxicity evaluation of the tested compound and its proposed degradation products was also estimated using the computer program TEST (Toxicity Estimation Software Tool).
\end{abstract}

Keywords: crizotinib, stability testing, degradation products, UHPLC, MS/MS, degradation pathway, toxicity prediction.

\section{INTRODUCTION}

C ANCER is the leading cause of death worldwide according to the World Health Organization. ${ }^{[1]}$ After breast cancer, lung cancer is the most common cancer in humans, with an estimated 2.21 million deaths in 2020.[1,2] About $80-85 \%$ of lung cancers are non-small cell lung cancer (NSCLC) as the dominant type. ${ }^{[2,3]}$ Since the cancer cells grow rapidly and metastasize easily, the treatment of choice is mainly surgery, chemotherapy and radiotherapy. First generation tyrosine kinase inhibitors have been used to treat NSCLC, but they are unable to inhibit the kinase activity of the fusion protein formed between the protein (EML4) and anaplastic lymphoma kinase (ALK). ${ }^{[3]}$ Therefore, studies focused on the discovery and development of new alternative drugs for the treatment of NSCLC including patients with EML4- ALK fusion proteins.

Crizotinib is a small molecule synthesized as a novel inhibitor of the receptor tyrosine kinase, anaplastic lymphoma kinase (ALK), as a drug target in NSCLC. It also shows antitumor activity on hepatocyte growth factor receptor (HGFR), cells with MET amplification. ${ }^{[4,5]}$ As a dual inhibitor, crizotinib causes direct suppression of tumor cell growth or survival and has potent antiangiogenic activity. ${ }^{\left[{ }^{[6]}\right.}$ Due to its great activity and clinical benefit shown in phase I and II studies in advanced; ALK-positive lung cancer, crizotinib was rapidly approved by the Food and Drug Administration (FDA) in 2011 under the trade name Xalkori. $[2,3]$

It is chemically described as 3-[1R-1-(2, 6-dichloro-3fluorophenyl)ethoxy]-5-(1-piperidin-4-yl-pyrazol-4-yl)pyridine-2-amine. ${ }^{[7]}$

This compound is a non-hygroscopic white to pale yellow powder, soluble in organic solvents such as ethanol and dimethyl sulfoxide (DMSO) and sparingly soluble in aqueous buffers. It has an asymmetric center of $R$ configuration and a thermodynamically stable crystalline form. ${ }^{[6,8]}$ It can be in the form of pyridinium cation ( $p K_{a}$ 5.6) and piperidinium cation with $\mathrm{p} K_{\mathrm{a}} 9.4 .^{[9]}$

Considering the fact that chemical stability of drugs has a great impact on the efficacy and safety of the drug, it

This work is licensed under a Creative Commons Attribution 4.0 International License. 
is necessary to conduct stability tests by forced degradation studies under different environmental factors as per to the guidance of $\mathrm{ICH} \cdot{ }^{[10]}$

Forced degradation studies are conducted to determine the intrinsic stability of the drug, identify probable degradation products, elucidate the structure of degradation products and their degradation pathways, and reveal the degradation mechanisms of the drug. ${ }^{[11]}$ The main purpose of conducting these studies is to develop stabilityindicating analytical methods for easy and routine analysis of drug substances and any resulting degradation products. ${ }^{[10-12]}$ The most widely used analytical method for separation and quantitative analysis of drug substances and their impurities is reversed phase high performance liquid chromatography (RP-HPLC) coupled with UV detector due to its compatibility with organic and aqueous solutions, high sensitivity, precision and ability to detect polar compounds. ${ }^{[10,11]}$ Hyphenation techniques such as LC-MS or LCNMR can be used for qualitative analysis and structural characterization of degradation products. ${ }^{[10]}$

Few chromatographic methods for crizotinib analysis based on liquid chromatography-tandem mass spectrometry $^{[13-15]}$ and UV detector ${ }^{[7,16,17]}$ have been published in the literature. Currently, to the author's knowledge, there are no previously reported methods for the qualitative analysis and characterization of new compounds formed by forced degradation of crizotinib. Therefore, the aim of the present work was to investigate the stability of crizotinib under acidic, basic, oxidative, photolytic and thermal conditions and to characterize newly formed degradation products by UHPLC-MS/ MS analysis.

\section{MATERIALS AND METHODS}

\section{Chemicals and Reagents}

The active pharmaceutical ingredient, crizotinib was obtained from Cayman Chemical (Michigan, United States). Acetonitrile (HPLC grade) was purchased from J. T. Baker (Phillipsburg, NJ, United States), potassium dihydrogen phosphate from Merck (Darmstadt, Germany) and ethanol from Kefo (Ljubljana, Slovenia). $30 \% \mathrm{H}_{2} \mathrm{O}_{2}$ (p.a.) and $\mathrm{NaOH}$ were purchased from Gram-mol (Zagreb, Croatia), and $\mathrm{HCl}$ (p.a.) from Honeywell, Fluka (Austria). Ultrapure water was prepared using a Millipore Simplicity UV water treatment system (Millipore, Paris, France).

\section{Preparation of Standard Solution and Sample Solution}

$1 \mathrm{mg}$ of crizotinib was weighed and transferred to a volumetric flask containing $5 \mathrm{~mL}$. The solid was dissolved in $2 \mathrm{~mL}$ of ethanol and then the volume was made up to the mark with ultrapure water to achieve a crizotinib concentration of $200 \mu \mathrm{g} \mathrm{mL}$. For all experiments, a mixture of water and ethanol in a $3: 2(\mathrm{v} / \mathrm{v})$ ratio was used as diluent.

\section{Forced Degradation Studies}

Forced degradation of crizotinib was performed according to the guideline $\mathrm{ICH} .{ }^{[18]}$ The study was performed using 200 $\mu \mathrm{g} \mathrm{mL} \mathrm{L}^{-1}$ solution of crizotinib. Five forced degradation experiments were performed to test the stability of the compound under the following conditions: acid and base hydrolysis, oxidation, heat and light.

The hydrolysis stress study included experiments on the forced degradation of the drug molecule under acidic and basic conditions. A volume of $0.5 \mathrm{~mL}$ of the selected concentration of $\mathrm{HCl}$ or $\mathrm{NaOH}(0.5 \mathrm{M})$ was added to $2 \mathrm{~mL}$ of crizotinib solution. After six hours at room temperature, the resulting solutions were neutralized with $0.5 \mathrm{~mL}$ of $\mathrm{NaOH}(0.5 \mathrm{M})$ and $0.5 \mathrm{~mL}$ of $\mathrm{HCl}(0.5 \mathrm{M})$ and diluted to $5 \mathrm{~mL}$ with diluent.

Oxidative stress testing was performed by mixing 2 $\mathrm{mL}$ of crizotinib solution with $1 \mathrm{~mL}$ of $10 \% \mathrm{H}_{2} \mathrm{O}_{2}$ for six hours at room temperature and then diluted to $5 \mathrm{~mL}$.

Thermal stability study was performed on liquid and solid samples. Thermal degradation of crizotinib solution was performed by keeping $2 \mathrm{~mL}$ of $200 \mu \mathrm{g} \mathrm{mL}^{-1}$ standard solution in a water bath at $80^{\circ} \mathrm{C}$ for 6 hours. The resulting solution was diluted to $5 \mathrm{~mL}$ with diluent. Thermal stability in solid form was tested by exposing crizotinib to dry heat at $100{ }^{\circ} \mathrm{C}$. After heating for 24 hours, $1 \mathrm{mg}$ of the sample was transferred to a volumetric flask containing $5 \mathrm{~mL}$ and dissolved in diluent for further analysis.

The photostability assay of crizotinib was performed in a photostability simulator Suntest CPS+ (Atlas, Germany). The crizotinib sample (200 $\left.\mu \mathrm{g} \mathrm{mL}^{-1}\right)$ was exposed to UV-A radiation (200 $\mathrm{Wh} \mathrm{m}^{-2}$ ) and visible radiation (1.2 million lux hours) for 15 hours.

\section{UHPLC-Mass Spectrometry Conditions}

An Agilent UHPLC system (Santa Clara, CA, SAD) coupled with a Agilent Infinity 6550 system time-of-flight mass spectrometer as detector (Santa Clara, CA, USA) was used for the separation and identification of crizotinib and the major degradation products formed in the stress stability assay. A C18 Waters Acquity BEH column $(100 \mathrm{~mm} \times$ $2.1 \mathrm{~mm}, 1.7 \mu \mathrm{m}$ ) was used as the stationary phase, while the mobile phase consisted of a $0.1 \%$ formic acid in water as solvent $A$ and acetonitrile as solvent $B$. The flow rate was $0.4 \mathrm{~mL} \mathrm{~min}{ }^{-1}$ with the gradient elution described in Table 1 . Sample ionization was performed in positive electrospray mode. The parameters for MS analysis were as follows: fragmentation voltage at $175 \mathrm{~V}$, capillary voltage at $3000 \mathrm{~V}$, drying gas temperature $200^{\circ} \mathrm{C}$, drying gas flow rate $14 \mathrm{~L} \mathrm{~min}^{-1}$, nebulizer pressure $35 \mathrm{psi}$. Nebulizer and collision 
Table 1. UHPLC gradient method for MS analysis.

\begin{tabular}{ccc}
\hline Time $/ \min$ & $\mathrm{A} / \%(v / v)$ & $\mathrm{B} / \%(v / v)$ \\
\hline 2.00 & 95 & 5 \\
5.00 & 85 & 15 \\
15.00 & 55 & 45 \\
16.00 & 20 & 80 \\
16.01 & 90 & 10 \\
Inject volume $/ \mu \mathrm{L}$ & 4 & \\
Flow rate $/ \mathrm{mL} \mathrm{min}$ & \\
\hline
\end{tabular}

gas was nitrogen. Data acquisition was performed using Agilent Mass Hunter 2003-2007 Data Acquisition for QTOF B.01.04 (B84) software.

\section{Computational Assessment of Toxicity}

To estimate the toxicity (developmental toxicity and mutagenicity) and bioaccumulation factor of crizotinib and its major tentative degradation products based on different QSAR models, Toxicity Estimation Software Tool (TEST) was used. Although QSAR models cannot completely replace actual tests, they are commonly used for risk prediction and registration of new compounds. In addition, many existing substances on the market do not have a complete data set on their hazards, making models a useful tool for prioritizing existing substances for further risk assessment. ${ }^{[19,20]}$

\section{RESULT AND DISCUSSION}

\section{Degradation of Crizotinib Due to Different Stress Conditions}

The forced degradation study of the drug was carried out under different chemical and environmental conditions mentioned above, to identify the possible chemical reactions and degradation products or impurities that may affect the stability of the main compound.

The degradation of crizotinib was observed during oxidative degradation, forming three major degradation products (DPs): DP-1 at RT $9.594 \mathrm{~min}, \mathrm{DP}-2$ at RT $10.228 \mathrm{~min}$ and DP-3 at RT 12.866 min (Figure 1). Crizotinib proved to be stable under hydrolysis, photolysis and thermal conditions as no degradation products were obtained compared to the untreated solution which is in agreement with the previously published forced degradation study of crizotinib by Bandla and Ganapaty ${ }^{[7]}$ (Figure 2 and Figure 3).

Notwithstanding of the fact that Bandla and Ganapaty indicate that crizotinib is stable under the conditions studied, they still note that the net degradation was found to be within limits. The same net degradation was observed in studies with other drugs for the treatment

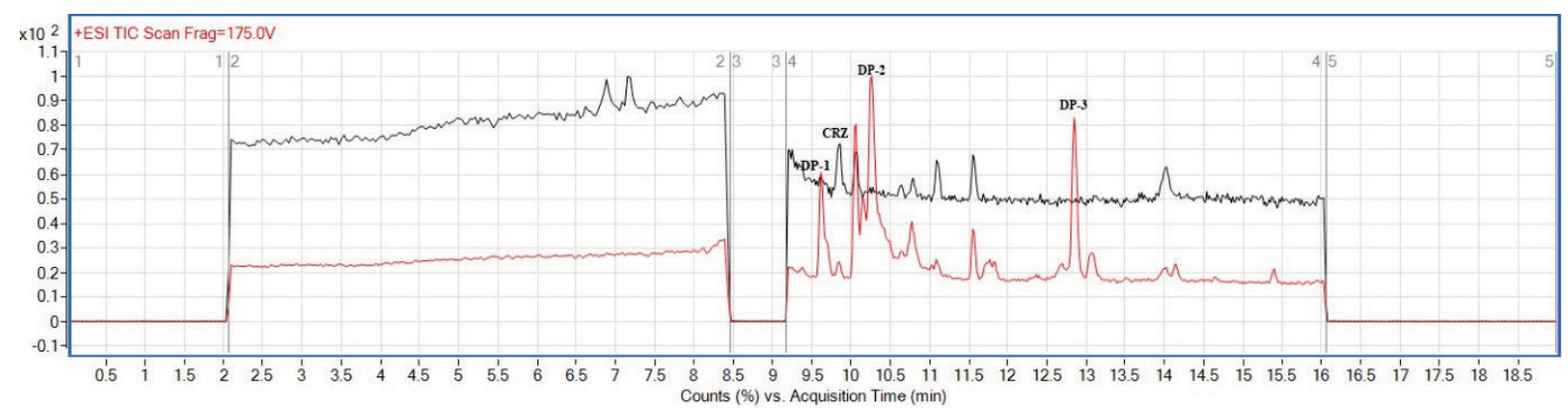

Figure 1. Crizotinib degradation products formed under oxidative conditions.

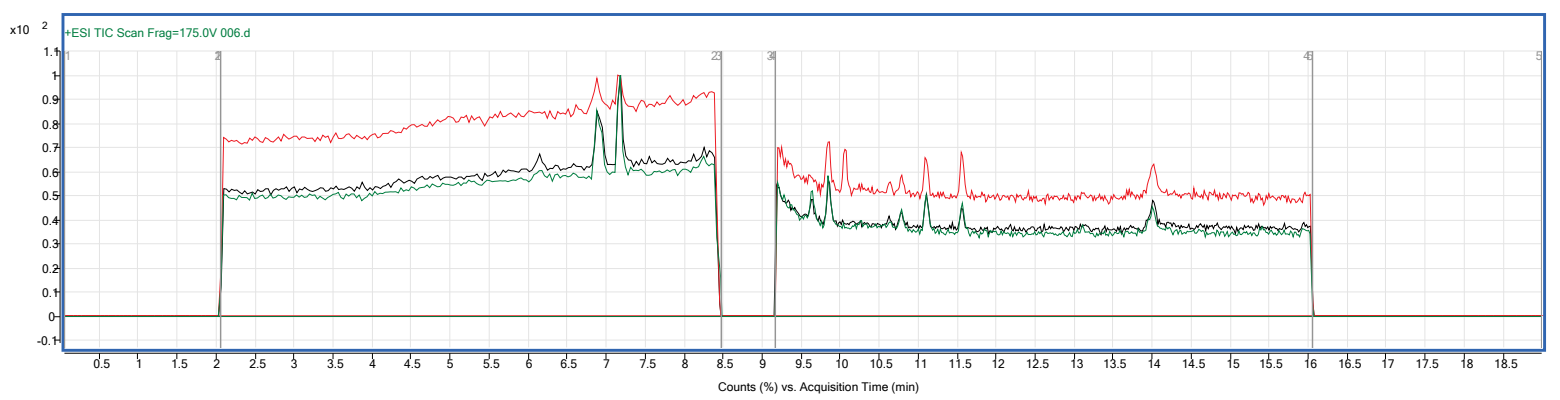

Figure 2. Overlapped chromatograms of untreated crizotinib (red) and degradation products under acid (green) and basic degradation (black) processes. 


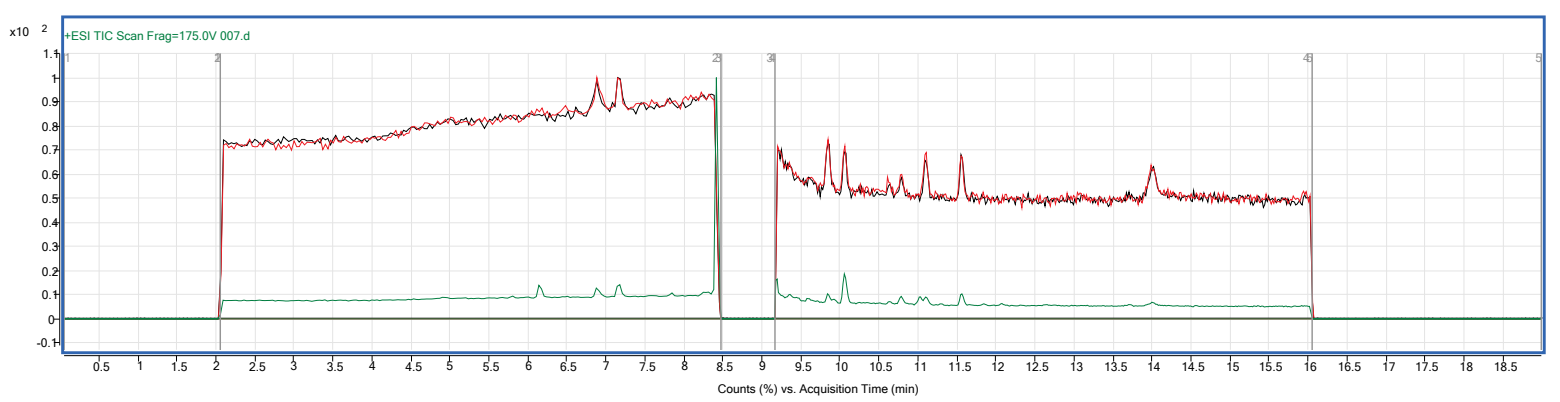

Figure 3. Overlapped chromatograms of untreated crizotinib (red) and photolytic and thermal degradation products (green).

of lung cancer such as axitinib ${ }^{[21]}$ while in the case of ceritinib ${ }^{[22]}$ a slightly more pronounced degradation was observed. However, none of the aforementioned papers reported the structures of the resulting degradation products.

\section{Identification of the Degradation Products}

The major degradation products formed by oxidation were identified and characterized by liquid chromatography-high resolution tandem mass spectrometry analysis (UHPLCHRMS/MS) in positive ESI mode. The newly observed peaks in the chromatogram (Figure 1) were assigned to the following compounds: DP-1 with $m / z 466[\mathrm{M}+\mathrm{H}]^{+}, \mathrm{DP}-2$ with $\mathrm{m} / \mathrm{z} 496$ $[\mathrm{M}+\mathrm{H}]^{+}$and DP-3 with $m / z 479[\mathrm{M}+\mathrm{H}]^{+}$. Table 2 shows retention times and optimal MS/MS conditions for crizotinib degradation products, while their structures are proposed in Table 3.

Table 2. Retention times and MS/MS conditions for crizotinib degradation products.

\begin{tabular}{ccccccc}
\hline & Retention time / min & \% RSD of Rt & Precur-sor ion $(\mathrm{m} / \mathrm{z})$ & Fragmentor voltage / V & Collision energy / eV & Product ions $(\mathrm{m} / \mathrm{z})$ \\
\hline DP-1 & 9.594 & 0.45 & 466 & 175 & 0 & $367,276,177$ \\
DP-2 & 10.228 & 0.94 & 496 & 175 & 0 & $480,324,288,177$ \\
DP-3 & 12.866 & 0.56 & 479 & 175 & 20 & $449,380,258$ \\
\hline
\end{tabular}

Table 3. Proposed structures of major oxidative degradation products.

Molecular weight




\section{STRUCTURE ELUCIDATION}

\section{Crizotinib}

Figure 4 shows the mass spectrum of crizotinib fragmentation and its characteristic product ions at $m / z 367,260$ and 177 .

The protonated molecule of crizotinib was observed in the mass spectrum at $m / z 450$. The fragment ions I and II at $m / z 367$ and 260 were the result of fragmentation of the piperidine ring and 2-ethyl-1,3-dichloro-4-fluorophenyl ring, respectively, from the parent molecule crizotinib. The cleavage of the piperidine ring from the fragment ion II led to the formation of product ion III with $m / z 177$ (Figure 5). The proposed degradation pathway of crizotinib during oxidative degradation was presented in Scheme 1 and described in detail below.

\section{Degradation Product 1}

High resolution QTOF mass spectrometer shows the mass spectrum of DP-1 (Figure 6).

In addition to the stable molecular ion of

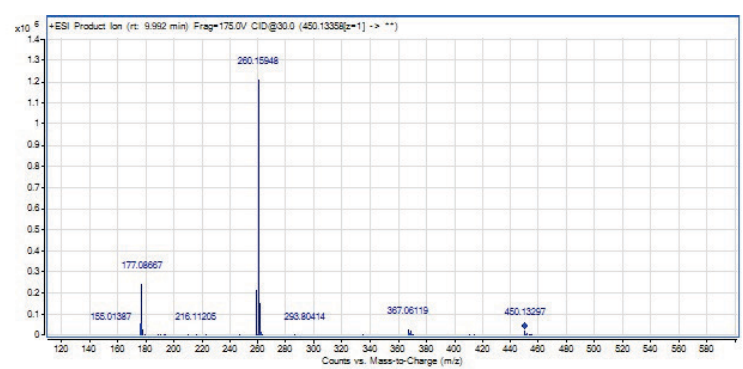

Figure 4. Mass spectrum of crizotinib.

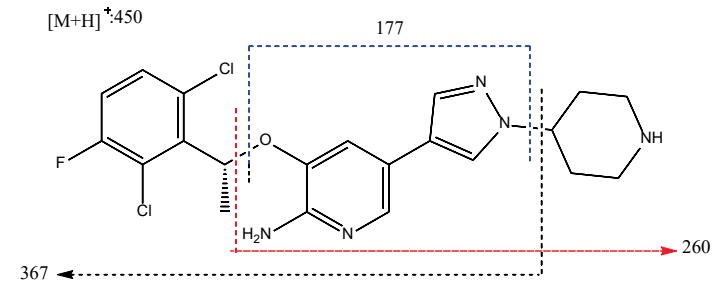

Figure 5. The proposed fragmentation of crizotinib.

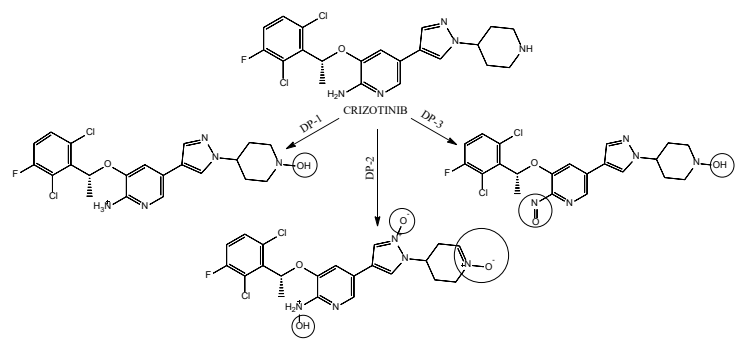

Scheme 1. Suggested degradation pathway of crizotinib during the oxidative degradation. degradation product 1 at $m / z$ 466, peaks of lower intensity at $m / z 367,276$ and 177 formed by fragmentation of DP-1 can be seen in Figure 6. The molecular ion of DP-1 was formed by oxidation of the nitrogen atom on the piperidine ring to the hydroxylamine of crizotinib. Fragment I with $\mathrm{m} / \mathrm{z} 367$ was generated by cleavage of the $\mathrm{N}-\mathrm{C}$ bond between the pyrazole and $\mathrm{N}$-hydroxy piperidine rings. Another fragmentation of fragment I formed the fragment II with $m / z$ 177. These peaks were characteristic ions in the mass spectrum of crizotinib, as described previously. The peak III with $\mathrm{m} / \mathrm{z} 276$ was also observed as a result of $\mathrm{C}-\mathrm{O}$ fragmentation, due to the loss of the 1,3-dichloro-4-fluoro2-ethylphenyl unit from the crizotinib molecule. Possible structures and fragmentation pathway of DP-1 was proposed in Scheme 2.

\section{Degradation Product 2}

MS/MS spectrum of the degradation product DP-2 is shown in Figure 7.

According to the mass spectrum of DP-2 (Figure 7), the stable crizotinib $\mathrm{N}$-oxide (DP-2) is formed with one molecular ion at $m / z$ 496. The mass spectrum also showed some fragment ions of low intensity characterized by the following $\mathrm{m} / \mathrm{z}$ values: $480,324,288$ and 177 . The fragment

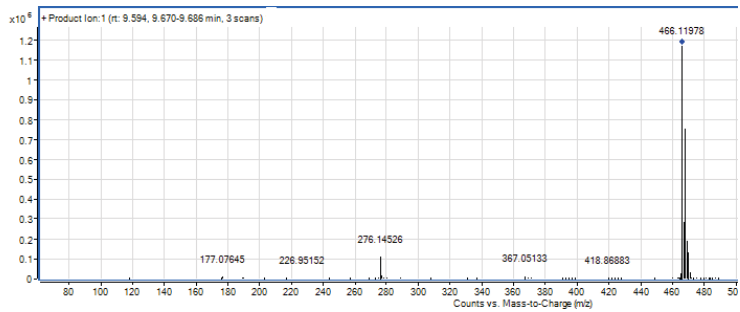

Figure 6. MS/MS spectrum of DP-1.

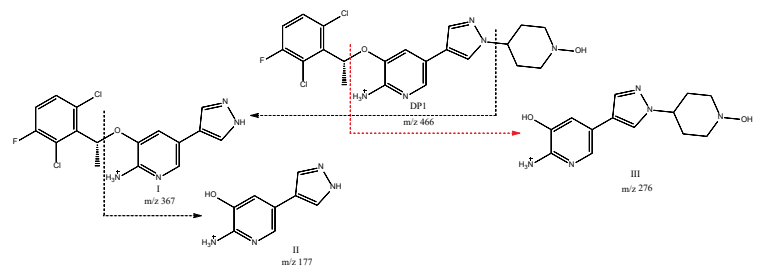

Scheme 2. The proposed fragmentation pathway of DP-1.

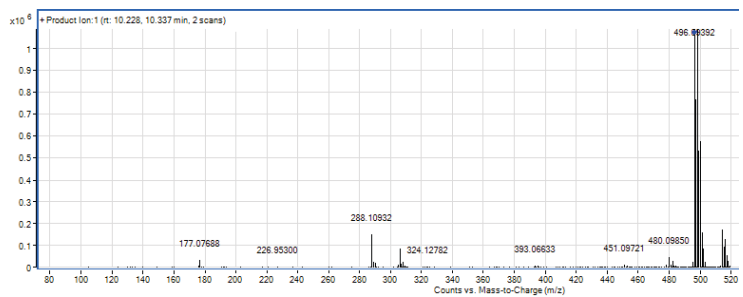

Figure 7. MS/MS spectrum of DP-2. 


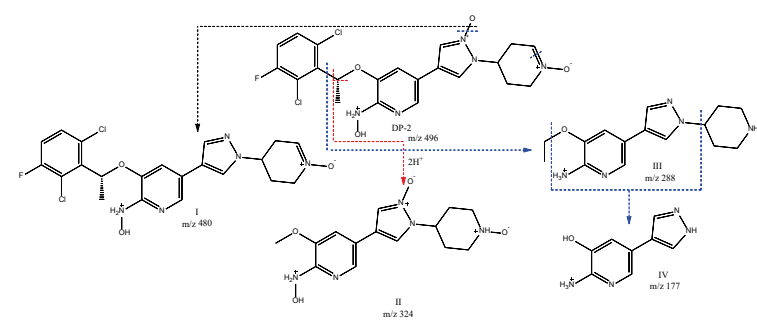

Scheme 3. The proposed fragmentation pathway of DP-2.

Table 4. Toxicity assessment of crizotinib and degradation products formed during forced degradation.

\begin{tabular}{cccc}
\hline Analyte & $\begin{array}{c}\text { Developmental } \\
\text { toxicity }\end{array}$ & $\begin{array}{c}\text { Bioaccumulation } \\
\text { factor Log } 10\end{array}$ & Mutagenicity \\
\hline Crizotinib & $+(0.23)$ & 2.00 & $+(0.53)$ \\
DP-1 & N/A & 1.81 & $+(0.67)$ \\
DP-2 & N/A & 2.17 & $\mathrm{~N} / \mathrm{A}$ \\
DP-3 & $+(0.82)$ & 2.73 & $+(0.58)$ \\
\hline
\end{tabular}

ion I with $\mathrm{m} / \mathrm{z} 480$ was formed by the loss of oxygen from the pyrazole ring. The fragment II indicates loss of the trisubstituted benzene ring, as does the fragment III with further fragmentation of the hydroxyl group from the aminopyridine ring and $\mathrm{N}-\mathrm{C}$ double bond cleavage with elimination of oxygen from the heterocyclic amines. The fragment IV $(m / z \quad 177)$ is also a characteristic ion of crizotinib and DP-1 fragmentation, as mentioned earlier. The proposed fragmentation pathway of DP-2 is shown in Scheme 3.

\section{Degradation Product 3}

The MS/MS spectrum of the degradation product DP- 3 is shown in Figure 8.

The fragment ion with $\mathrm{m} / \mathrm{z}$ value 479 represents the molecular ion of the degradation product DP-3. It was

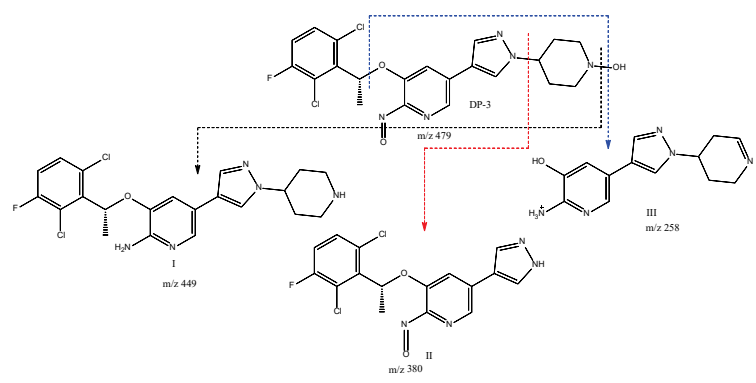

Scheme 4. The proposed fragmentation pathway of DP-3.

formed by the addition of the mass of 29 amu to the crizotinib molecule, suggesting the formation of crizotinib $\mathrm{N}$-oxide by oxidation of the piperidine and aminopyridine ring. The fragments formed by DP-3 fragmentation are outlined on the MS/MS spectrum of DP-3 (Figure 8). Fragment I with $\mathrm{m} / \mathrm{z} 449$ was formed by fragmentation of the hydroxyl group from the aminopyridine ring and the $\mathrm{N}$ $\mathrm{O}$ bond, accompanied by cleavage of the double $\mathrm{N}-\mathrm{C}$ bond from the piperidine ring. The fragment II with $\mathrm{m} / \mathrm{z} 380$ represents a stable peak with the highest intensity in the mass spectrum of DP-3 fragmentation. It was formed by the mass loss of $99 \mathrm{amu}$, fragmenting the piperidine oxide ring from the rest of the DP-3 molecule. The fragment III was formed by fragmentation of the four-substituted phenyl ring with loss of the hydroxyl group from the aminosubstitued pyridine ring and the $\mathrm{N}-\mathrm{O}$ bond of the piperidine, indicating the formation of the peak with $\mathrm{m} / \mathrm{z}$ 258. Their proposed structures are shown in Scheme 4.

\section{Computational Assessment of Crizotinib and Its DPs Properties}

Since forced degradation experiments result in the formation of various intermediates, it is necessary to evaluate the toxicity of the newly formed compounds and the extent of their effects on humans, animals, and the

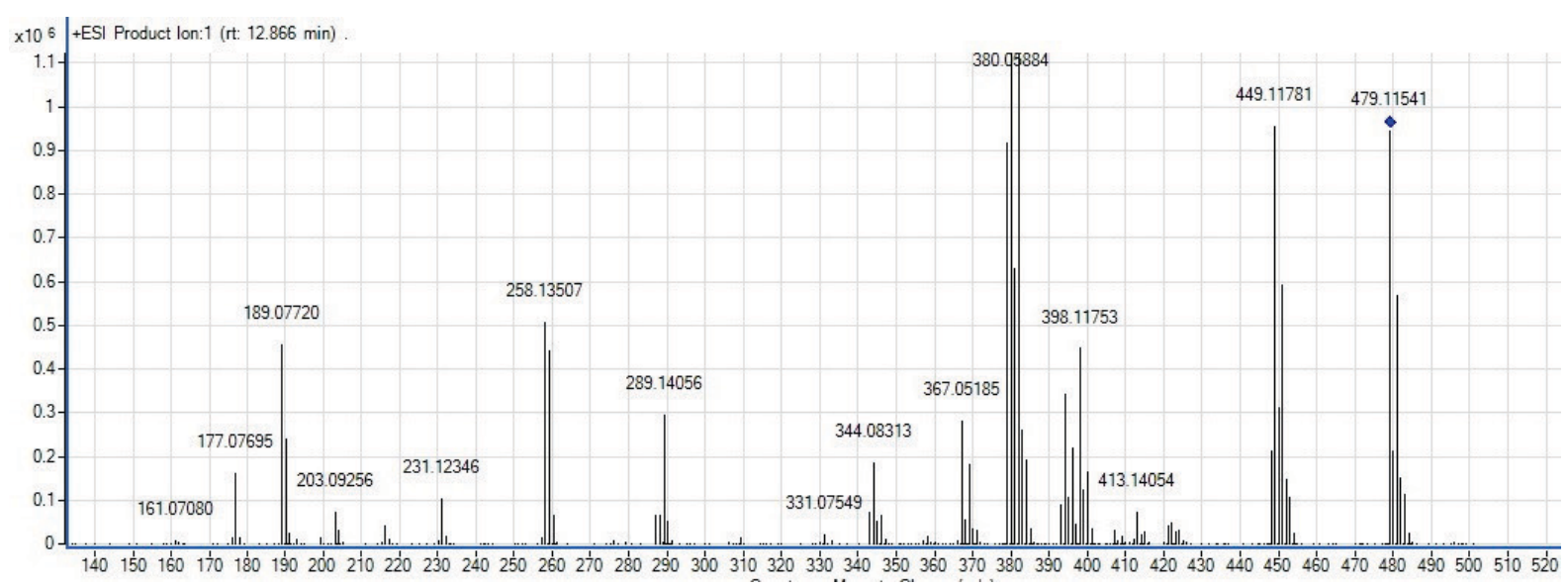

Figure $8 . \mathrm{MS} / \mathrm{MS}$ spectrum of DP-3. 
environment in general. Although the use of living organisms is the most desirable way to test the toxicity of a molecule, numerous studies, such as Trawiński and Skibiński (2019) using the example of clozapine, ${ }^{[23]}$ use calculations based on the molecular structure of the compound, as used in this case by the software TEST.

Developmental toxicity was estimated for the parent compound crizotinib and found that the mentioned drug can be classified as non-toxic with a probability of 0.23 , and DP-3 (probability of 0.82 ). Consensus prediction is considered unreliable as only one prediction can be made, therefore toxicity was not calculated for the other two DPs. Mutagenicity, expressed as the probability of the Ames test, showed a slightly higher mutagenic potential for DP-1 than crizotinib and DP-3, while mutagenicity could not be assessed for DP-2. The predicted bioaccumulation factor (BAF) for all analytes tested ranged from 64.56-537.03, with DP-2 and DP-3 as compounds with a high tendency to bioaccumulate, while crizotinib and DP-1 are thought to accumulate moderately. ${ }^{[24]}$ The results were presented in Table 4. It should be noted that the values obtained for DP-1 and DP-2 were predicted by the nearest neighbor method based on an average of three chemicals similar to the one tested.

\section{CONCLUSION}

In this study, high-resolution mass spectrometry was used for the first time to describe the fragmentation pathways of crizotinib and its major degradation products (QTOF$\mathrm{MS} / \mathrm{MS}$ ). Since the stress degradation conditions are not the same for each compound, the studies performed for crizotinib showed that the three major degradation products are formed by an oxidation experiment. Based on the spectral data obtained, the degradation products were interpreted by proposing their possible fragmentation pathways. Crizotinib was shown to be a hydrolytically, photo- and thermally stable under the applied stress conditions. The computational assessment of developmental toxicity and mutagenicity assumes a positive value for crizotinib and predicts that this compound may cause malformations upon contact with humans or animals. All compounds tested were found to be susceptible to moderate or high bioaccumulation. It should be noted that the resulting degradation products are present at low concentrations, so some other experiments (in vivo, in vitro) would likely eliminate the toxicity parameters obtained. Such software predictions are useful to prioritize and assess the risk of emerging components before actual commercialization.

Acknowledgment. This study did not receive any specific support from funding agencies in the public, commercial, or not-for-profit sectors.

\section{REFERENCES}

[1] WHO, Cancer, 2011 https://www.who.int/newsroom/fact-sheets/detail/cancer

[2] G. Hamilton, B. Rath, O. Burghuber, Expert Opin. Drug Metab. Toxicol. 2015, 11(4), 1. https://doi.org/10.1517/17425255.2015.1021685

[3] T. A. Wani, I. A. Darwish, Braz. J. of Pharm. Sci. 2015, 51(2), 439. https://doi.org/10.1590/S1984-82502015000200021

[4] J. J. Cui, M. Tran-Dubé, H. Shen, M. Nambu, P. P. Kung, M. Pairish, L. Jia, J. Meng, L. Funk, I. Botrous, M. McTigue, N. Grodsky, K. Ryan, E. Padrique, G. Alton, S. Timofeevski, S. Yamazaki, Q. Li, H. Zou, J. Christensen, B. Mroczkowski, B. S. Bender, R. S. Kania, M. P. Edwards, J. Med. Chem. 2011, 54, 63426363. https://doi.org/10.1021/jm2007613

[5] J. Tanizaki, I. Okamoto, K. Okamoto, K. Takezawa, K. Kuwata, H. Yamaguchi, K. Nakagawa, J. Thorac. Oncol. 2011, 6, 1624-1631. https://doi.org/10.1097/JTO.0b013e31822591e9

[6] T. Nwizu, R. Kanteti, I. Kawada, C. Rolle, E. E. Vokes, R. Salgia, Drugs Future. 2011, 36(2), 91-99. https://doi.org/10.1358/dof.2011.036.02.1584112

[7] J. Bandla, S. Ganapaty, Int. J. Pharm. Sci. and Res. 2018, 9, 1493-1498.

[8] Product Information, Crizotinib, Cayman Chemical 2018 https://www.caymanchem.com/pdfs/12087.pdf

[9] A. Sahu, K. Prabhash, V. Noronha, A. Joshi, S. Desai, South Asian Journal of Cancer 2013, 2, 91-97. https://doi.org/10.4103/2278-330X.110506

[10] M. Blessy, R. D. Patel, P. N. Prajapati, Y. K. Agrawal, J. Pharm. Anal. 2014, 4, 159-165. https://doi.org/10.1016/j.jpha.2013.09.003

[11] F. Iram, H. Iram, A. Iqbal, A. Husain, J. Anal. Pharm. Res. 2016, 3(6), 00073.

[12] E. Tamizi, A. Jouyban, Eur. J. Pharm. Biopharm. 2015, 98, 26-46. https://doi.org/10.1016/j.ejpb.2015.10.016

[13] F. Qiu, Y. Gu, T. Wang, Y. Gao, X. Li, X. Gao, S. Cheng, Biomed. Chromatogr. 2016, 30, 962-968. https://doi.org/10.1002/bmc.3636

[14] R. W. Sparidans, S. C. Tang, L. N., Nguyen, A. H Schinkel, J.H.M Schellens, J. H. Beijnen, J. Chromatogr. B: Anal. Technol. Biomed. Life Sci. 2012, 905, 150-154.

https://doi.org/10.1016/j.jchromb.2012.08.021

[15] M. S. Roberts, D. C. Turner, A. Broniscer, C. F. Stewart, J. Chromatogr. B 2014, 960, 151-157. https://doi.org/10.1016/j.jchromb.2014.04.035

[16] V. K. Bontha, S. Emmadi, S. Gandhe, IOSR J. Pharm. Biol. Sci. 2016, 11, 93-103. 
[17] P. B. Jadhav, V. Shejwal, Int. J. Pharm. Pharm. Res. 2017, 9, 100-106.

https://doi.org/10.22159/ijpps.2017v9i9.20684

[18] International Conference on Harmonization (ICH), Stability Testing of new drug substances and products, Q1A (R2), IFPMA, Geneva, 2003.

[19] TEST (Toxicity Estimation Software Tool), 2020, https://cfpub.epa.gov/si/si_public_record_report.c $\mathrm{fm}$ ? Lab=NRMRL\&dirEntryld $=243050$

[20] QSAR models, 2020,

https://www.chemsafetypro.com/Topics/CRA/Whe n_to_Use_QSAR_for_Chemical_Substance_Registra tion_and_Common_QSAR_Models.html
[21] G. Ashok, S. Mondal, Indian J. Pharm. Biol. Res. 2017, 5, 1. https://doi.org/10.30750/ijpbr.5.3.1

[22] V. S. Adhao, J. Sharma, M. Thakare, Indonesian J. Pharm. 2017, 28, 241-248.

https://doi.org/10.14499/indonesianjpharm28iss4p p241

[23] J. Trawiński, R. Skibiński, Sci. Total Environ. 2019, 665, 557-567.

https://doi.org/10.1016/j.scitotenv.2019.02.124

[24] C. Franke, G. Studinger, G. S. Berger, S. Böhling, U. Bruckmann, D. Cohors-Fresenborg, U. Jöhncke, Chemosphere 1994, 29, 1501-1514.

https://doi.org/10.1016/0045-6535(94)90281-X 